\title{
Atuação da doula na atenção à mulher durante o ciclo gravídico puerperal: uma revisão integrativa
}

\author{
The role of the doula in women's care during the pregnancy-puerperal cycle: an \\ integrative review
}
El papel de la doula en el cuidado de la mujer durante el ciclo embarazo-puerperal: una revisión integradora

Raquel Xavier de Souza Saito ${ }^{1 *}$, Arielly Menezes dos Santos ${ }^{1}$, Brenda dos Santos Queiroz ${ }^{1}$, Milena Silva Costa ${ }^{1}$.

\section{RESUMO}

Objetivo: Revisar as potencialidades do cuidado da doula no acompanhamento da mulher durante o ciclo gravídico. Métodos: Trata-se de uma revisão integrativa da literatura, construída a partir da busca nas bases de dados: Biblioteca Virtual de Saúde (BVS), Scientific Electronic Library (SCIELO), Literatura Latinoamericana e do Caribe em Ciências da Saúde (LILACS) e Base de Dados em Enfermagem (BDENF). Os descritores utilizados foram consultados na lista de Descritores em Ciências da Saúde (DECs) e são: "doulas" e "parto humanizado", sendo utilizados artigos em português e inglês dos últimos 10 anos e foram selecionados 8 estudos. Resultados: As evidências são de que a inserção da doula no acompanhamento da gestante contribui para a humanização da atenção e apoio à mulher que passa a ser atendida e acompanhada de forma singular. Essas relações contribuem para que grande parte das mulheres escolha 0 parto normal e natural. Considerações finais: A doula permite o resgate do sentido de dar à luz de forma natural e de poder vivenciar esse momento único, deixando de fora toda a estigmatização social imposta ao longo do tempo, portanto, é necessária a conscientização da equipe multidisciplinar para que a doula seja inserida no processo do trabalho de parto.

Palavras-chave: Doula, Parto humanizado, Humanização.

\begin{abstract}
Objective: To review the potential of doula care in monitoring women during the pregnancy cycle. Methods: This is an integrative literature review, built from a search in the following databases: Virtual Health Library (VHL), Scientific Electronic Library (SCIELO), Latin American and Caribbean Health Sciences Literature (LILACS) and Database in Nursing (BDENF). The descriptors used were consulted in the list of Health Sciences Descriptors (DECs) and are: "doulas" and "humanized childbirth", being used articles in Portuguese and English from the last 10 years and 8 studies were selected. Results: Evidence is that the insertion of the doula in the monitoring of pregnant women contributes to the humanization of care and support to the woman who starts to be cared for and accompanied in a unique way. These relationships contribute to the fact that most women choose normal and natural childbirth. Final considerations: The doula allows the rescue of the meaning of giving birth in a natural way and being able to experience this unique moment, leaving out all the social stigmatization imposed over time, therefore, it is necessary to raise awareness of the multidisciplinary team so that the doula is inserted in the labor process.
\end{abstract}

Key words: Doula, Humanized birth, Humanization.

${ }^{1}$ Faculdade Santa Marcelina (FASM), São Paulo - SP. *E-mail: doulasfasm@hotmail.com

SUBMETIDO EM: 9/2021

ACEITO EM: 9/2021

PUBLICADO EM: 9/2021 


\section{RESUMEN}

Objetivo: Revisar el potencial del cuidado de las doulas en el seguimiento de las mujeres durante el ciclo del embarazo. Métodos: Se trata de una revisión bibliográfica integradora, construida a partir de una búsqueda en las siguientes bases de datos: Biblioteca Virtual en Salud (BVS), Biblioteca Electrónica Científica (SCIELO), Literatura Latinoamericana y del Caribe en Ciencias de la Salud (LILACS) y Base de Datos en Enfermería (BDENF). Los descriptores utilizados fueron consultados en la lista de Descriptores de Ciencias de la Salud (DECs) y son: "doulas" y "parto humanizado", utilizándose artículos en portugués e inglés de los últimos 10 años y se seleccionaron 8 estudios. Resultados: La evidencia es que la inserción de la doula en el seguimiento de gestantes contribuye a la humanización del cuidado y apoyo a la mujer que comienza a ser atendida y acompañada de manera única. Estas relaciones contribuyen al hecho de que la mayoría de las mujeres eligen el parto normal y natural. Consideraciones finales: La doula permite rescatar el significado de dar a luz de forma natural y poder vivir este momento único, dejando fuera toda la estigmatización social impuesta a lo largo del tiempo, por ello, es necesario concienciar al equipo multidisciplinar para que que la doula se inserta en el proceso de parto.

Palabras clave: Doula, Nacimiento humanizado, Humanización.

\section{INTRODUÇÃO}

A palavra doula é de origem grega e significa mulher escrava ou servente. Com o decorrer da história, representa aquela que ajuda a mulher após o parto, em atividades domésticas e no cuidado do bebê. Essa profissional pode ter ou não formação técnica na área da saúde, ela orienta e acompanha a mulher durante o parto e entre os objetivos de sua ação estão: passar segurança, tranquilidade e encorajamento no ciclo gravídico puerperal. Dessa forma, todo nascimento é único e toda mulher tem direito a uma experiência de parto positiva, norteada por respeito as suas escolhas (GRECIA LRM, et al., 2019).

Em 1976, nos Estados Unidos, Dana Raphael divulgou e descreveu o trabalho de uma doula, que durante um parto auxiliou a mulher de forma integral e humanizada. A procura por essa profissional começou a ser significativa, pois ela passou a ser considerada uma das possibilidades para redução das taxas de partos cesáreas. Exemplos de locais que oferecem capacitação e informações sobre a profissão estão crescendo, como a "Associação de Doulas da América do Norte (DONA)" e as entidades "Doulas do Brasil" e "Associação Nacional de Doulas (ANDO)" (SILVA RM, et al., 2012).

As doulas, foram mulheres conhecidas como parteiras ao longo da história e passaram a realizar os partos em ambientes familiares. Na maioria das situações elas tinham vínculos com as parturientes e com suas famílias durante todo processo de parto. No entanto, com o decorrer do tempo, a assistência à mulher passou para médicos e enfermeiros obstetras, a ser realizada em âmbito hospitalar (SILVA RM, et al., 2012). Essa mudança contribuiu para que o número de partos cesáreas aumentassem, superando a quantidade de partos normais. De 2015 a 2017, ocorreram 8.799.003 partos no Brasil, dentre eles, 4.884 .313 cesáreas, assim nas regiões sudeste e nordeste do país estão as maiores concentrações desse tipo de parto (MINISTÉRIO DA SAÚDE, 2017).

De acordo com dados do Sistema de Informação sobre Mortalidade, em 2015, o Brasil registrou 1.738 casos de morte materna devido os problemas durante ou após o parto e em 2016, foram registrados 1.463 casos, queda de $16 \%$ em relação ao ano anterior. Diante disso, práticas, condutas e conhecimentos baseados no desenvolvimento saudável no processo do parto e do nascimento impõe a necessidade de se individualizar e valorizar as necessidades das mulheres (MINISTÉRIO DA SAÚDE, 2018).

A Assembleia Legislativa do Estado de São Paulo apresenta a Lei 15.759 de 25 de março de 2015 cujo art. $1^{\circ}$ diz que toda gestante tem direito a receber assistência humanizada durante 0 parto nos estabelecimentos públicos de saúde do Estado. $O$ art. $4^{\circ}$ assegura o direito da mulher, após ser diagnosticada grávida, ter um plano individual de parto, que inclui o estabelecimento onde será prestada a assistência do pré-natal e assegura, igualmente, o direito da mulher a ter uma equipe responsável pela assistência. 
A Portaria do Ministério da Saúde n 306, de 28 de março de 2016, aprovou diretrizes para de atenção à gestante, com ênfase na redução do número de partos cesáreas (MINISTÉRIO DA SAÚDE, 2016). Já em 2017, foram divulgadas as "Diretrizes de Atenção à Gestante para o parto normal", aprovada pela Portaria N ${ }^{\circ}$ 353. No qual, direcionam equipes de saúde e mulheres a tomada de decisão da melhor via de parto. Por sua vez, a recomendação № 038, de 23 de agosto de 2019, defende que o parto saudável é aquele que acontece de modo natural e em ambiente humanizado. Dentre todas essas ponderações, o parto cesariano somente deveria ser indicado em casos em que a mulher ou o bebê estejam em situações de riscos (MINISTÉRIO DA SAÚDE, 2017 e MINISTÉRIO DA SAÚDE, 2019).

O estudo de Silva RM, et al. (2012) defende que, o aumento dos partos normais em detrimento aos partos cesáreas depende e pode acontecer com a criação das casas de parto, ampliação do número de enfermeiras obstetrizes e resgate ao parto realizado pelas doulas. Entre as estratégias para que este tipo de parto se constitua a principal escolha da gestante está à inserção da doula no acompanhamento da mulher no ciclo gravídico puerperal.

Outros estudos demonstram também que esse tipo de suporte pode ajudar, igualmente, a romper ciclos viciosos de negligências, violência, privação e até evitar a morte neonatal. Caso houver ações indesejáveis de enfermeiras e médicos, será justamente o acompanhamento da doula que servirá para a humanização da assistência. Frequentes situações desconfortáveis que costumam compor o relato de mulheres sobre o momento do parto, como o médico dizer "pare de gritar, na hora de fazer você não gritou", podem ser evitadas e atenuadas pela aplicação de técnicas da doula, auxiliando no conforto e na expulsão do bebê. Com isso, o vínculo dessa professional nesse momento, é indispensável para atender as necessidades tanto da gestante, quanto dos familiares. O principal papel é respeitar e estimular a mulher a exercer sua autonomia dando importância aos aspectos psicoemocionais, que possibilitam identificar queixas transitórias ou aquelas mais graves que podem ocorrer durante esse processo (BARBOSA MBB, et al., 2018).

O parto humanizado, bem como a humanização da assistência prestada propõe um novo olhar para o momento do parto para que se compreenda a verdadeira experiência de dar à luz, de forma humana e fisiológica. Antigamente, as avós e as mães faziam dessa forma, sem nenhuma intervenção médica ou cirúrgica. Acolher, ouvir, orientar e criar vínculo entre os que compartilham a experiência é um dos aspectos mais fundamentais que regem o conceito de parto humanizado (POSSATI AB, el al., 2017).

De acordo com a Diretriz Nacional de Assistência ao Parto Normal em 2016, relata que a gestação e o parto normal de baixo risco, podem ser acompanhados por enfermeiras obstetras, médicos obstetras, obstetrizes e doulas. Dentre eles, a doula pode atuar como uma das condutoras em partos normais/naturais de baixo risco em casas de parto (MINISTÉRIO DA SAÚDE, 2017)

Logo, parte-se do pressuposto de que as doulas contribuem para o parto humanizado, pois podem fornecer apoio e instrução à gestante e à família desta. Em face de tais fatores, este estudo teve por objetivo investigar e analisar as potencialidades no cuidado exercido pela doula para a humanização do parto e no acompanhamento da mulher durante o ciclo gravídico puerperal.

\section{MÉTODOS}

Trata-se de uma revisão integrativa da literatura, construída a partir da busca nas bases de dados: Biblioteca Virtual de Saúde (BVS), Scientific Electronic Library (SciELO), Literatura Latino-americana e do Caribe em Ciências da Saúde (LILACS) e Base de Dados em Enfermagem (BDENF) no dia 7 de setembro de 2020. Os descritores utilizados foram consultados na lista de Descritores em Ciências da Saúde (DeCS) e são: "doulas" e "parto humanizado". A pesquisa surgiu de uma hipótese: a inclusão da doula no acompanhamento da mulher durante o ciclo gravídico puerperal é de grande importância e assegura atenção integral e humanizada à mulher?

Utilizou-se para nortear a escolha desses estudos, os critérios de inclusão: estudos disponíveis na íntegra, na língua portuguesa ou inglesa, publicados nos últimos 10 anos e que apresentassem relação com o objetivo dessa pesquisa. Ao buscar nas bases de dados, por meio dos DECS e filtros aplicados, foram encontrados 
27 artigos e desses foram selecionados 8 artigos. Dessa forma, todo o processo encontra-se sintetizado na ferramenta PRISMA na Figura 1.

Figura 1 - Fluxograma da seleção dos artigos adaptado do modelo PRISMA.
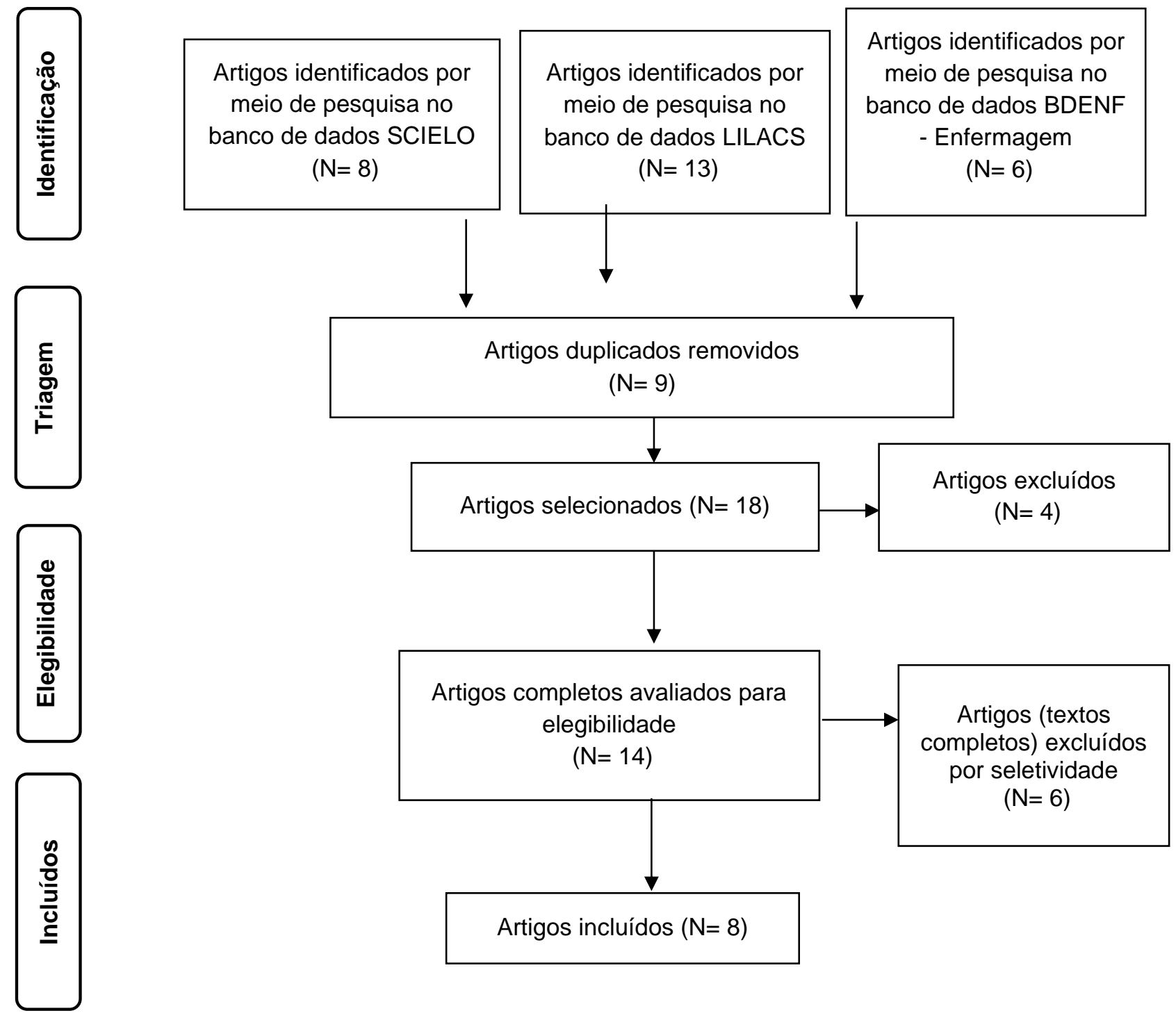

Fonte: Saito RX et al., 2021.

\section{RESULTADOS E DISCUSSÃO}

Após leitura na integra dos 8 estudos, os núcleos centrais de cada artigo são apresentados a seguir no Quadro 1. Quanto ao tipo de estudo mais prevalente, obteve-se o exploratório-descritivo-qualitativo. Todavia, constava também, dentre eles, uma metassíntese e um recorte de dissertação. Todos destacam que a atuação da doula no ciclo gravídico puerperal resulta em humanização da atenção.

Diante de tal acúmulo de evidências científicas, pode-se reafirmar e evidenciar a importância da doula não só na composição da equipe, mas também durante todo o ciclo gravídico puerperal. Com isso, a gravidez e o parto se constituem em experiências singulares e inexplicáveis para a maioria das mulheres. No decorrer da gestação, essas mulheres passam por alterações fisiológicas materno-fetais que precisam de atenção multiprofissional, o que inclui a enfermeira obstetra, médico obstetra e a doula (LIMA PO, et al., 2019). 
Quadro 1 - Síntese dos artigos selecionados por autor/ano de publicação.

\begin{tabular}{|c|c|c|c|c|}
\hline Autor (ano) & Título & $\begin{array}{l}\text { Desenho/ } \\
\text { Estudo }\end{array}$ & Objetivos & Resultados \\
\hline $\begin{array}{c}\text { Souza KRF e } \\
\text { Dias MD } \\
(2010)\end{array}$ & $\begin{array}{l}\text { História oral: a } \\
\text { experiência das doulas no } \\
\text { cuidado à mulher. }\end{array}$ & $\begin{array}{l}\text { Qualitativo, } \\
\text { descritivo. }\end{array}$ & $\begin{array}{l}\text { Mostrar a possibilidade de } \\
\text { utilização da História Oral como } \\
\text { referencial metodológico para } \\
\text { compreender o significado da } \\
\text { experiência das doulas durante o } \\
\text { processo de parto e nascimento } \\
\text { em uma maternidade pública. }\end{array}$ & $\begin{array}{c}\text { Participaram } 9 \text { doulas, as entrevistas foram realizadas na } \\
\text { própria maternidade, analisando a história oral de cada uma. } \\
\text { Emergiram dois eixos temáticos que trazem a experiência } \\
\text { das doulas: o primeiro é um caminho para a humanização e o } \\
\text { segundo é acolhendo e criando vínculos entre doulas e } \\
\text { mulheres. }\end{array}$ \\
\hline $\begin{array}{l}\text { Silva RM, et } \\
\text { al. (2012) }\end{array}$ & $\begin{array}{l}\text { Evidências qualitativas } \\
\text { sobre o acompanhamento } \\
\text { por doulas no trabalho de } \\
\text { parto e no parto. }\end{array}$ & $\begin{array}{l}\text { Metassíntese } \\
\text { (estudos } \\
\text { qualitativos). }\end{array}$ & $\begin{array}{l}\text { Elaborar uma metassíntese com } \\
\text { as evidências sobre o trabalho } \\
\text { das doulas no acompanhamento } \\
\text { às mulheres em trabalho de parto } \\
\text { e de parto. }\end{array}$ & $\begin{array}{c}\text { Foram selecionados } 7 \text { artigos e destes emergiram quatro } \\
\text { categorias: suporte proporcionado por doulas; experiências } \\
\text { das parturientes; relacionamento profissional; e opiniões e } \\
\text { experiências dos profissionais. }\end{array}$ \\
\hline $\begin{array}{c}\text { Barbosa MBB } \\
\text { et al. (2018) }\end{array}$ & $\begin{array}{l}\text { Doulas como dispositivos } \\
\text { para humanização do } \\
\text { parto hospitalar: do } \\
\text { voluntariado à } \\
\text { mercantilização. }\end{array}$ & $\begin{array}{l}\text { Exploratório, } \\
\text { descritivo, } \\
\text { qualitativo. }\end{array}$ & $\begin{array}{l}\text { Analisar a partir da perspectiva } \\
\text { das doulas, sua inserção na } \\
\text { assistência ao parto em hospital } \\
\text { público de João Pessoa. }\end{array}$ & $\begin{array}{c}\text { Pesquisa com } 6 \text { doulas do Projeto de Doulas Comunitárias } \\
\text { Voluntárias, desenvolvido a partir da parceria da Secretaria } \\
\text { Extraordinária de Políticas Públicas para Mulheres (SEPPM). } \\
\text { Para as doulas participantes da Tenda do Conto, a principal } \\
\text { motivação que as impulsionou a assumir essa ocupação é o } \\
\text { desejo de ajudar gestantes a terem um parto digno e } \\
\text { humanizado. }\end{array}$ \\
\hline
\end{tabular}




\begin{tabular}{|c|c|c|c|c|}
\hline Autor (ano) & Título & $\begin{array}{l}\text { Desenho/ } \\
\text { Estudo }\end{array}$ & Objetivos & Resultados \\
\hline $\begin{array}{c}\text { Santos S e } \\
\text { Fabbro MRC } \\
\text { (2018) }\end{array}$ & $\begin{array}{c}\text { A difícil tarefa de escolher } \\
\text { o parto natural. }\end{array}$ & $\begin{array}{l}\text { Qualitativo; } \\
\text { Recorte de } \\
\text { dissertação. }\end{array}$ & $\begin{array}{l}\text { Compreender motivações de } \\
\text { mulheres usuárias do Epi-no à } \\
\text { escolha do parto natural entre } \\
2013-2015 \text {, descrevendo } \\
\text { elementos facilitadores (EF). }\end{array}$ & $\begin{array}{l}\text { Pesquisa realizada por meio de relatos de } 7 \text { mulheres, } \\
\text { gravados em áudio, transcritos e analisados. Idade } 22-38 \\
\text { anos; todos os partos vaginais, } 2 \text { tiveram laceração }\left(1^{\circ} \text { grau) e }\right. \\
1 \text { episiotomia, } 6 \text { primíparas, } 2 \text { multíparas, idade gestacional } \\
\text { variou de } 36-41 \text { semanas, } 3 \text { realizaram, além do Epi-no, } \\
\text { massagem, contração e relaxamento, } 6 \text { tiveram doulas e a } \\
\text { escolaridade variou entre } 3^{\circ} \text { grau e pós-graduação. } \\
\text { Elaboraram-se } 14 \text { temáticas, agrupadas em EF e ED } \\
\text { (elementos dificultadores): Conhecendo sua história; apoio da } \\
\text { família/profissional/doula; Preparação física e psicológica para } \\
\text { o parto; e, reconhecendo as fases do trabalho de parto. }\end{array}$ \\
\hline $\begin{array}{c}\text { Borja TJ, et al. } \\
\qquad(2018)\end{array}$ & $\begin{array}{l}\text { O cuidado prestado por } \\
\text { doulas em uma } \\
\text { maternidade pública: o } \\
\text { olhar das puérperas. }\end{array}$ & $\begin{array}{l}\text { Exploratório, } \\
\text { descritivo, } \\
\text { qualitativo. }\end{array}$ & $\begin{array}{l}\text { Analisar a percepção das } \\
\text { mulheres sobre o cuidado } \\
\text { prestado por doulas durante o } \\
\text { trabalho de parto, o parto e pós- } \\
\text { parto imediato em uma } \\
\text { maternidade pública de João } \\
\text { Pessoa - PB. }\end{array}$ & $\begin{array}{l}\text { A amostra foi de } 8 \text { puérperas idade entre } 20-37 \text { anos, as } \\
\text { entrevistas foram realizadas nas residências das participantes } \\
\text { e duraram, em média, } 40 \text { minutos cada. As puérperas } \\
\text { compreendem o trabalho da doula como adjuvante para } \\
\text { diminuição da dor e desconforto no trabalho de parto e no } \\
\text { parto. Enunciaram que o vínculo estabelecido contribuiu para } \\
\text { tornar o parto um momento positivo e afetuoso. }\end{array}$ \\
\hline $\begin{array}{l}\text { Silva LCC, et } \\
\text { al. (2018) }\end{array}$ & $\begin{array}{c}\text { Percepção de mulheres } \\
\text { sobre o parto e o papel } \\
\text { da doula. }\end{array}$ & $\begin{array}{c}\text { Exploratório, } \\
\text { qualitativo. }\end{array}$ & $\begin{array}{l}\text { Analisar a percepção de mulheres } \\
\text { sobre o parto e sobre a figura da } \\
\text { doula no processo de parturição. }\end{array}$ & $\begin{array}{c}\text { Foram entrevistadas } 9 \text { mulheres, com idades entre } 19 \text { a } 35 \\
\text { anos que tiveram uma gestação de baixo risco e que foram } \\
\text { acompanhadas por doulas durante a gestação, parto e/ou no } \\
\text { período pós-parto. Após a interpretação dos dados obtidos } \\
\text { através das falas das entrevistas foi possível identificar três } \\
\text { categorias: Práticas Institucionais e Ambiência; Enfrentamento } \\
\text { da dor; Presença da Doula e Importância da Equipe. }\end{array}$ \\
\hline
\end{tabular}




\begin{tabular}{|c|c|c|c|c|}
\hline Autor (ano) & Título & $\begin{array}{c}\text { Desenho/ } \\
\text { Estudo }\end{array}$ & Objetivos & Resultados \\
\hline $\begin{array}{c}\text { Lima PO, et al. } \\
(2019)\end{array}$ & $\begin{array}{c}\text { Compreensão sobre o } \\
\text { trabalho da doula em uma } \\
\text { maternidade do Vale do } \\
\text { Jequitinhonha - MG. }\end{array}$ & $\begin{array}{c}\text { Descritivo } \\
\text { qualitativo }\end{array}$ & $\begin{array}{c}\text { Analisar a compreensão das } \\
\text { puérperas, das doulas e da } \\
\text { equipe assistencial sobre a } \\
\text { presença da doula durante o } \\
\text { processo de parturição das } \\
\text { gestantes. }\end{array}$ & $\begin{array}{c}\text { Entrevistados } 19 \text { participantes, sendo 10 da equipe de saúde, } \\
5 \text { das doulas e } 4 \text { das puérperas. Após análise, foram } \\
\text { identificadas três categorias, sendo elas: presença da doula } \\
\text { durante o trabalho de parto das gestantes e seus significados; } \\
\text { acompanhamento da doula durante o trabalho de parto das } \\
\text { gestantes e suas melhorias a influência da doulagem na } \\
\text { formação acadêmica. A presença das doulas trouxe para a } \\
\text { parturiente segurança, apoio, humanização e } \\
\text { acompanhamento do processo de parto. Para a equipe trouxe } \\
\text { conforto e tranquilidade. As doulas pontuaram benefícios na } \\
\text { formação acadêmica. }\end{array}$ \\
\hline $\begin{array}{c}\text { Grecia LMR, } \\
\text { et al. (2019) }\end{array}$ & $\begin{array}{c}\text { Percepção e ações de } \\
\text { doulas no processo de } \\
\text { humanização do parto. }\end{array}$ & $\begin{array}{c}\text { Exploratório, } \\
\text { descritivo, } \\
\text { qualitativo }\end{array}$ & $\begin{array}{c}\text { Identificar o que significa para as } \\
\text { doulas o parto humanizado e } \\
\text { quais ações elas desenvolvem no } \\
\text { processo de humanização com } \\
\text { parturientes e puérperas. }\end{array}$ & $\begin{array}{c}\text { As participantes da pesquisa foram cinco doulas. Os dados } \\
\text { foram obtidos por meio da técnica de entrevista, com uso de } \\
\text { um instrumento do tipo roteiro semiestruturado, aplicado no } \\
\text { horário de trabalho de forma individual. Identificaram-se duas } \\
\text { categorias temáticas - significado de parto humanizado na } \\
\text { visão das doulas, seu papel frente à assistência à parturiente e } \\
\text { à puérpera. Cabendo-lhes assistir integralmente a mulher, } \\
\text { proporcionando-lhe acolhimento, empoderamento, conforto, } \\
\text { segurança e suporte emocional de encorajamento. }\end{array}$ \\
\hline
\end{tabular}

Fonte: Saito RXS, et al., 2021. 
O parto, ápice dessa experiência, deveria transcorrer de forma natural e humanizada pelos profissionais implicados. No entanto, evidências comprovam que as institucionalizações do parto em hospitais acabam por envolver falta de preparo e a mercantilização do parto cesárea, assim contribui para que este se firme como a principal escolha de parto (BARBOSA MBB, et al., 2018).

Diante disso o Programa de Humanização do Pré-Natal e Nascimento (PHPN) traz recomendações clínicas e diretrizes para o acompanhamento pré-natal, parto e puerpério. Ele apresenta possibilidades de abordagens humanizadas baseadas em evidências, como por exemplo: um digno acolhimento à tríade mulher-bebê-família; apoio de acompanhante; decisão quanto à posição do nascimento; apoio e construção de vínculo entre os profissionais e a parturiente e espaços para informações e trocas de experiências (MINISTÉRIO DA SAÚDE, 2000; BORJA TJ, et al., 2018; POSSATI AB, el al., 2017).

Nesse contexto, a inclusão da doula tem significância e deve ser considerada, principalmente por se constituir tecnologia leve, com grande potencial na redução de riscos, complicações e na humanização do parto. O acompanhamento da doula amplia possibilidades de indicação e êxito na realização do parto natural, assegura apoio e confiança a gestante para que esse momento se torne uma experiência positiva e única. Além disso, diminui os riscos de morbimortalidade materno-fetal implícitos numa intervenção cirúrgica que poderia ser evitada (BORJA TJ, et al., 2018).

Assim, a atuação da doula se torna indispensável nesse momento, pois ela traz consigo um significado de parto humanizado de forma simples e eficaz, que resulta em um acolhimento positivo e seguro à mulher sobre suas decisões, proporcionando, por conseguinte, a autonomia. Durante todo o ciclo gravídico puerperal, a doula concede à mulher potencialidades no cuidado de forma humanizada (SILVA LCC, et al., 2018; LIMA LO, 2017). Humanizar o parto significa não expor a mulher a intervenções desnecessárias que podem resultar em complicações. Diferentemente dos demais membros da equipe, a doula está no cenário de parto e suas atribuições e atenção estão direcionadas exclusivamente à gestante (BORJA TJ, et al., 2018; LIMA LO, 2017).

Santos S e Fabbro MRC (2018) chamam a atenção para o fato de que a luta por igualdade, justiça social e liberdade ainda é um desafio enfrentado pelas mulheres em relação a sua saúde sexual e reprodutiva. A escolha do tipo de parto, além de ser delicada, é um momento em que a mulher precisa de apoio e cuidados específicos. Nesse momento, conhecimentos sobre riscos e benefícios devem ser apresentados na programação do pré-natal, em espaços para esclarecimentos, por meio de suporte psicológico e troca de experiências que precisam ser oferecidas e divulgadas.

A equipe deve entender que em muitos casos a insegurança das gestantes e, consequentemente, a opção pelo parto cesárea decorre de relatos de outras mulheres multíparas, que nem sempre contribuem com experiências agradáveis e que, em muitas situações, as transmitem recheadas de mitos e informações incorretas sobre o assunto. Logo, o caminho é o apoio profissional, que se inicia no acolhimento, durante 0 pré-natal aonde os encontros devem se mostrar educativos e informativos e contemplar orientações sobre a escolha do parto (SANTOS S e FABBRO MRC, 2018).

Experiências positivas no ciclo gravídico puerperal dependem de redes de apoio, do nível de formação, da estrutura de serviços e de informações que são passadas. A doula, com base na especificidade de suas competências, propicia as mulheres espaços para exteriorizar suas necessidades em relação à maternidade. No acompanhamento, a mulher é reconhecida como um ser biopsicossocial e, o parto normal, apresentado como experiência positiva, natural. Assim, estigmas e angústias são dissipados no acolhimento e no respeito a visão de mundo de cada mulher (SANTOS S e FABBRO MRC, 2018 e LIMA LO, 2017).

A missão da doula é contra hegemônica ao modelo biomédico instalado, em que a mulher é violentada fisicamente e verbalmente no trabalho de parto. Casos de violências obstétricas são também uma realidade e, no entanto, as mulheres não ecoam suas vozes para que essa realidade se extinga. Desta forma, a doula, busca encorajar essas mulheres para que lutem contra esse modelo de atenção de modo que a humanização do parto seja restituída, ou seja, fazer humano aquilo que é humano (GRECIA RML, et al., 2019).

Humanizar o parto significa não expor a mulher a intervenções desnecessárias que podem resultar em complicações. Diferentemente dos demais membros da equipe, a doula está no cenário de parto e suas 
atribuições e atenção estão direcionadas exclusivamente à gestante (BORJA TJ, et al., 2018; LIMA LO, 2017). O vínculo entre profissionais, parturientes e familiares é mais amplo e constitui-se por meio do encontro da mulher com o seu sagrado feminino. Nesse encontro, o reconhecimento do corpo, da mente e de sua força não se resume somente no cuidado, mas está relacionado ao preparo do ambiente, de si mesmo, da família, da equipe e da conexão ali presente (SILVA LCC, et al., 2018; SOUZA KRF e DIAS MD, 2010).

Mesmo reconhecidos os benefícios do acompanhamento da doula, ainda há muita resistência de profissionais que insistem em manter o modelo biomédico e mercantilizado para a indicação do tipo de parto. A escolha pelo parto cesárea é benéfica, sobretudo, para as instituições hospitalares e visa, na maioria das situações, lucro médico-institucional. No que se refere as mulheres, a preferência para o parto cesárea está relacionada ao acesso a anestesia para inibição da dor, a rapidez do nascimento e aos mitos de que essa intervenção é mais "segura" se comparada ao parto normal. Na maioria das situações, a mulher não sabe dos riscos materno-fetais de se submeter a uma cesárea, tampouco é instruída a considerar que a data do parto está diretamente relacionada ao momento em que a criança está preparada para o nascimento (BARBOSA MBB, et al., 2018).

A atuação da doula não exclui as atividades privativas de enfermagem ou de outros profissionais. Ao contrário, soma-se a elas de modo a contribuir para que os serviços prestados a parturiente e bebê transcorram de forma integral e singular. Os profissionais da saúde e puérperas são unanimes em afirmar a importância da doula no acompanhamento de mulheres durante o ciclo gravídico puerperal. Todos relataram mudanças positivas decorrentes do exercício da doula. Entretanto, observaram, ao mesmo tempo, falta de informações sobre as ações dessa profissional, tanto por parte das gestantes e puérperas, quanto dos profissionais da saúde, acarretando falta de valorização desse trabalho específico (LIMA PO, et al., 2019 e LIMA LO, 2017). Além disso, as evidências dos benefícios do acompanhamento da doula que compreende acalento físico e psicológico, práticas seguras de todo o processo de gestação, parto e pós-parto, resulta na atenção integral as necessidades da gestante (LIMA PO, et al., 2019 e SILVA RM, et al., 2012).

O movimento de resgate para inserção da doula no cuidado da gestante caminha no sentido de assegurar direito e acesso ao trabalho de parto humanizado. A doula, apesar de sua longa existência, se mostra como potencialidade inovadora no suporte à gestante, puérpera e ao recém-nascido e possibilita romper fronteiras e muros que são criados e sustentados por medos, falta de informações e inseguranças. Constata-se que a influência positiva da doula no ciclo gravídico puerperal precisa ser gradual, estimulada, valorizada e mais acessível, com o intuito de garantir o direito da mulher em receber a assistência humanizada (BARBOSA MBB, et al., 2018).

\section{CONSIDERAÇÕES FINAIS}

Ao explorar potencialidades do cuidado da doula para a humanização no acompanhamento da mulher durante o ciclo gravídico puerperal, evidenciam-se, com base nos diferentes autores, que a inclusão dessa profissional representa possibilidades de transformação da experiência do parto humanizado e diminuição do parto cesárea. A doula permite, por fim, o resgate do sentido de dar à luz de forma natural e de poder vivenciar esse momento único, deixando de fora toda a estigmatização social imposta ao longo do tempo. Portanto, é necessária a conscientização da equipe multidisciplinar para que a doula seja inserida no processo do trabalho de parto.

\section{REFERÊNCIAS}

1. ASSEMBLEIA LEGISLATIVA dO ESTAdO DE SÃO PAULO. Governo do Estado de São Paulo. Lei 15.759, de 25 de março de 2015 - Assegura o direito do parto humanizado nos estabelecimentos públicos de saúde do Estado e de outras providências. São Paulo: Assessoria Técnico-Legislativa. São Paulo, 2015. Disponível em: https://www.al.sp.gov.br/repositorio/legislacao/lei/2015/lei-15759-25.03.2015.html. Acesso em 06 de mar. de 2020

2. BARBOSA MBB, et al. Doulas como dispositivos para humanização do parto hospitalar: do voluntariado à mercantilização. Saúde Debate, 2018; 42(117): 412-424. 
3. BORJA TJ, et al. O cuidado prestado por doulas em uma maternidade pública: o olhar das puérperas. Revista de Enfermagem do Centro Oeste Mineiro. 2018; 8: 2878.

4. GRECIA LMR, et al. Percepção e ações de doulas no processo de humanização do parto. REME - Rev. Min. Enferm. 2019; 23: e-1209.

5. LIMA LO. Doula, sim! A importância das doulas na gestação, parto e puerpério. Seminário Internacional Fazendo Gênero 11 \& 13th Women's Worlds Congress (Canais Eletrônicos). 2017; 2-9.

6. LIMA PO, et al. Compreensão sobre o trabalho da doula em uma maternidade do Vale do Jequitinhonha - MG. Rev. Bras. Saude Mater. Infant, 2019; 19(3): 569-574.

7. MINISTÉRIO DA SAÚDE. Conselho Nacional de Saúde. Recomendação № 038, de 23 de agosto de 2019. Brasil, 2019. Disponível em: https://conselho.saude.gov.br/recomendacoes/2019/Reco038.pdf. Acesso em: 08 março 2020.

8. MINISTÉRIO DA SAÚDE. Diretrizes de Atenção à Gestante: a operação cesariana. Recomendação №179, p.8. Brasil, 2016. Disponível em: http://conitec.gov.br/images/Relatorios/2016/Relatorio_Diretrizes-Cesariana_final.pdf . Acesso em: 06 março 2020.

9. MINISTÉRIO DA SAÚDE. Diretrizes Nacionais de Assistência ao Parto Normal. Gabinete do Ministro. Portaria №353, de 14 de fevereiro de 2017. Diário oficial da União, ed. 36. Seção 1. p.37. Brasil, 2017. Disponível em: http://www.in.gov.br/materia/-/asset_publisher/Kujrw0TZC2Mb/content/id/20805342/do1-2017-02-20-portaria-n-353de-14-de-fevereiro-de-2017-20805260. Acesso em: 08 março 2020.

10. MINISTÉRIO DA SAÚDE. Maternidade segura: assistência ao parto normal: um guia prático, p. 9-14. Brasil, 2000. Disponível em: http://www.saude.mppr.mp.br/arquivos/File/kit_atencao_perinatal/manuais/assistencia_ao_parto_normal_2009.pdf. Acesso em: 08 mar.2020.

11. MINISTÉRIO DA SAÚDE. Ministério da saúde investe na redução da mortalidade materna. Brasil, 2018. Disponível em: $\quad$ https://www.gov.br/saude/pt-br/assuntos/noticias/ministerio-da-saude-investe-na-reducao-da-mortalidadematerna. Acesso em: 08 jul. 2020.

12. MINISTÉRIO DA SAÚDE. Sistema de informações nascidos vivos por região nos anos de 2015 a 2017. Brasil, 2017. Disponível em: http://tabnet.datasus.gov.br/cgi/tabcgi.exe?sinasc/cnv/nvuf.def. Acesso em: 06 março 2020.

13. POSSATI AB, et al. Humanização do parto: significados e percepções de enfermeiras. Esc Anna Nery. $2017 ; 2-6$.

14. SANTOS S, FABBRO MRC. A difícil tarefa de escolher o parto natural. Cienc. enferm., Concepción, $2018 ; 24: 11$.

15. SILVA LCC, et al. Percepção de mulheres sobre o parto e o papel da doula. Psicologia revista. 2018; ed 27: 357376.

16. SILVA RM, et al. Evidências qualitativas sobre o acompanhamento por doulas no trabalho de parto e no parto. Ciênc. saúde coletiva, Rio de Janeiro, 2012; 17(10): 2783-2794.

17. SOUZA KRF, DIAS MD. História oral: a experiência das doulas no cuidado à mulher. Acta paul. enferm. 2010; 23(4): 493-499. 